\title{
Tratamento de salvaguarda em situação de emergência: a atuação do IEB em acervo cedido pela Justiça Federal de São Paulo
}

Bianca Maria Abbade Dettino*

Chegada do acervo

No segundo semestre de 2005, o Instituto de Estudos Brasileiros da Universidade de São Paulo (IEB) foi nomeado responsável, pela Justiça Federal de São Paulo, pela guarda e administração provisória de parte do acervo que pertenceu ao Banco Santos, acervo que foi cedido pela Justiça Federal de São Paulo nos termos dos autos n 2005.61.81.900396-6 em trâmite na Sexta Vara Criminal Federal Especializada em Crimes contra o Sistema Financeiro Nacional e em Lavagem de Valores.

Ainda que em caráter provisório, a sua incorporação foi feita do mesmo modo que a de qualquer outro acervo destinado ao IEB; dessa forma, o primeiro contato com as peças ocorreu ainda no galpão utilizado como reserva técnica pelo banco. Não se possuía conhecimento prévio de que tipo de acervo seria ali encontrado, nem de seu estado de conservação, nem da destinação final de cada um dos objetos que compunham o acervo.

Independentemente dessas indefinições, o IEB formou uma equipe que, a princípio, possuía o objetivo de identificar os objetos que fossem interessantes para as linhas de trabalho e pesquisa desenvolvidas no Instituto. Não foi tarefa das mais fáceis, já que a quantidade de peças era enorme, as condições de trabalho, precárias - pois água e energia haviam sido desligadas e a manutenção era inexistente -, e o tempo, limitado.

Para dar conta da tarefa em tais condições, acertou-se com a Justiça Federal que se entraria na reserva técnica meio período por semana, sempre com o acompanhamento de dois oficiais de justiça. Durante dois meses, dirigiu-se ao galpão a equipe supervisionada por técnicos especializados do IEB, composta dos funcionários e de estagiários que exerciam atividades ligadas aos acervos do Instituto.

* supervisora da Coleção de Artes Visuais do IEB-USP. 
A partir da visita técnica realizada por docentes e funcionários desta Universidade, foi traçada a diretriz a ser seguida pelo IEB, que consistia em identificar dentro do galpão os seguintes núcleos de interesse: cartografia histórica, literatura de cordel e matrizes de xilogravura.

Mesmo com tal diretriz, a equipe não limitou sua atuação a esses núcleos, e sim seguiu o comprometimento profissional com um acervo cultural que necessitava de medidas de salvamento imediato, ainda que em detrimento da identificação peça a peça do material definido como prioritário.

Em virtude da inundação sofrida pelo galpão, que criou condições favoráveis à proliferação de fungos, bactérias e animais xilófagos, havia urgência na adoção de algumas medidas de salvamento. Dentre os objetos que necessitavam de intervenção imediata estavam toda a literatura de cordel, boa parte das matrizes de xilogravura, tapetes assinados pelo arquiteto Sílvio Oppenheim e um forro de igreja em madeira policromada composto de várias partes que estavam empilhadas. Essas peças foram as mais danificadas, pois estavam embaladas em material plástico, o que gerou acúmulo de água e sua não evaporação. Ao adotar medidas que favorecessem a ventilação, foi necessário o trabalho coordenado de várias pessoas, já que ora o material era extremamente volumoso, ora pesado demais devido à quantidade de água absorvida. Para garantir que as peças não piorassem, chamou-se a conservadora e restauradora Florence Maria White de Vera, especialista em restauro de objetos tridimensionais, para consultoria em relação à eficácia das medidas de salvamento adotadas.

Além disso, foi necessário extremo cuidado para que a infestação de micro-organismos não fosse prejudicial à saúde daqueles que manipulavam as peças, mesmo com o uso de materiais de proteção. Ademais, o galpão exalava cheiro assaz ruim, que nauseava a todos.

Utilizando material de proteção individual - touca, máscara e avental -, a equipe de trabalho se dividiu em algumas frentes: uma para levantar a cartografia histórica; outra para tomar medidas de salvamento relativas à literatura de cordel, bem como às matrizes de xilogravura; e, ainda, uma de exploração do galpão, objetivando identificar possíveis peças com estado de conservação comprometido.

Com este levantamento prévio, identificou-se todo o material que viria ao IEB. E assim, no final de 2005, a cartografia histórica, a literatura de cordel, as matrizes de xilogravura e metal e as xilogravuras chegaram à atual sede do Instituto. 


\section{Incorporação do acervo}

Com a chegada do material ao IEB, entrou-se em nova fase: realizar o inventário dessas peças, não só para cumprir a decisão judicial, mas para iniciar efetivamente os trabalhos museológicos e de pesquisa pertinentes.

Porém, parte do acervo não possuía sequer condições de manuseio, devido a seu estado de conservação. A partir dessa constatação, configuraram-se dois procedimentos básicos: o tratamento urgente para os ataques biológicos que prejudicavam sobremaneira qualquer contato com as obras; e a higienização mecânica dos objetos, acompanhada do levantamento de problemas pontuais apresentados para futura restauração.

\subsection{Acervo extremamente danificado}

A literatura de cordel e as matrizes de xilogravura foram imediatamente isoladas para evitar qualquer contaminação de fungo e cupim, não só de outros acervos, como também dos freqüentadores do IEB. Uma das salas do Instituto, a de tamanho mais adequado, foi preparada para receber provisoriamente o acervo, tendo sido guarnecida de estantes abertas que permitissem a ventilação do material após a retirada da embalagem de transporte do galpão para a sede do IEB.

\subsubsection{Literatura de cordel e xilogravura}

Os manuscritos e folhetos referentes à literatura de cordel somam em torno de 1.700 exemplares; as xilogravuras, aproximadamente 850. Todo esse material sofreu as conseqüências da alta umidade associada à temperatura variável. Assim, o primeiro passo era submetê-lo a uma ventilação constante, que eliminaria o foco do problema. 0 segundo passo consistiu na remoção da sujidade superficial, vale dizer, dos resíduos das colônias de fungos, pela higienização mecânica com trincha de cerdas macias. Aproveitando-se o manuseio individual das peças, retiraram-se materiais metálicos, como grampos e clipes, que por oxidarem danificavam ainda mais o suporte.

Para garantir sua conservação e integridade, os cordéis foram acondicionados em caixas de polipropileno, mais conhecido como poliondas, confeccionadas no próprio Instituto especialmente para este acervo.

É importante salientar que o trabalho seguiu uma metodologia segundo a qual durante os cuidados de conservação 
levantam-se também dados de catalogação básicos: no caso dos cordéis, título, autor e número de páginas. A partir dessa breve listagem, será possível traçar o universo do acervo e elaborar projetos que proponham o aprofundamento da pesquisa sobre o mesmo.

\subsubsection{Matrizes de xilogravura - uso do Irradiador Multipropósito de Cobalto-60}

As matrizes de xilogravura perfazem em torno de 3400 exemplares, que possuem diversos tamanhos e temas. Parte delas se encontrava sem qualquer invólucro, ou envolvidas por papel craft que continha a gravura de sua respectiva matriz impressa. Além disso, estavam tomadas por fungos e, em muitos casos, infestadas por cupins que as deterioravam muito. Tão logo o material chegou ao IEB, pesquisou-se a melhor solução para a infestação que se espraiava cada vez mais. Como já observamos, ele teve de ser isolado para que não contaminasse acervos já tratados e equilibrados. Mas a solução definitiva encontrada após o estudo do material foi a sua esterilização a partir do Irradiador Multipropósito de Cobalto-60. No Irradiador, as matrizes de xilogravura passam por uma câmara de irradiação a fim de eliminar as colônias de fungos, cupins ou qualquer outro organismo vivo. Esse tratamento foi possível graças à parceria do IEB com o Instituto de Pesquisas Energéticas e Nucleares da USP (IPEN) e, particularmente, à sensibilidade do Professor Doutor Paulo Rella, que se mostrou muito solícito frente à necessidade de ações imediatas em decorrência da situação do acervo.

Com isso, foi possível inaugurar o uso de uma vertente de tratamento que já vinha sendo pesquisada pelo IPEN e que pela primeira vez foi aplicada em uma estratégia de salvamento. Essa vertente se afigura como promissora para os acervos do IEB. Efetivamente, vêm sendo pesquisados os efeitos e níveis-limite da irradiação, com o propósito de verificar a possibilidade de submeter não só as matrizes de madeira à ação do Irradiador, mas também documentos em suporte de papel - o que viabilizaria a esterilização dos cordéis e xilogravuras, ampliando o leque de estratégias que compõe as operações de salvamento em geral.

Para encaminhar o material adequadamente ao IPEN, as matrizes foram colocadas em sacos plásticos de polietileno, pela especificidade de não possuírem cloro em sua composição, e identificados para controle. Após a irradiação a que o material foi exposto, houve a higienização de cada matriz para retirada da sujidade originada dos fungos e cupins, bem como seu acondicionamento em caixas de poliondas confeccionadas pela equipe 
do IEB. Devido à complexidade do salvamento e tratamento de conservação desta parte do acervo, deixar-se-á para uma próxima oportunidade o detalhamento de todo o processo. Adiantamos, porém, que para a continuidade do trabalho de conservação, restauro e acondicionamento dos manuscritos e xilogravuras obtivemos financiamento da Caixa Econômica Federal. Em um ano, todo o acervo estará disponível para consulta.

\subsection{Cartografia histórica}

0 trabalho com a cartografia histórica foi desenvolvido de maneira diversa, já que o acondicionamento deste núcleo o isolava da inundação, o que gerou poucos casos de intervenção de restauro. Dessa forma, aprofundou-se a pesquisa e a catalogação mapa a mapa. Boa parte desses mapas originou-se claramente do desmembramento de Atlas dos mais variados tipos e formatos, do século XVI ao XIX.

Para o gerenciamento da documentação construída a partir da catalogação e pesquisa dos mapas, elaborou-se um banco de dados com diversos tipos de informações, desde dados físicos e estado de conservação detalhados, até levantamentos provenientes da pesquisa. 0 banco já se encontra disponível para consulta no IEB.

A seguir, apresentamos o inventário de cada um dos quase 380 mapas com: número de identificação; denominação atribuída; datação; técnica de elaboração; e dimensões (altura X largura).

Inventário da cartografia histórica do acervo cedido pela Justiça Federal de São Paulo

A0000379 - Orbis Typus Universalis Iuxta Hydrographorum Traditionem, 1522. xilogravura s/ papel trapo, 35,6 X 48,5 cm.

A0000380 - Carta Marina Nuova Tavola, s.d.gravura em metal aquarelada s/ papel com polpa de madeira.

A0000381 - Typus Orbis Terrarum, 1570 - 1571. gravura em metal aquarelada s/ papel, 33,7 X $49,9 \mathrm{~cm}$.

A0000382 - Orbis Terrarum Compendiosa Descriptio, 1587. Gravura em metal aquarelada s/ papel com polpa de trapo, 28,7 X $52 \mathrm{~cm}$.

A0000384 - Peruvia, s.d. Gravura em metal s/ papel com polpa de madeira. 
A0000385_A - America, s.d. Gravura em metal aquarelada s/ papel, 37 X 49,9 cm.

A0000385_B - America, s.d. Gravura em metal aquarelada s/ papel, 37,1 X 50,5 cm.

A0000386 - America With Those Known Parts in That Unknowne Worlde - Both People and Manner - Of Buildings Discribed and Inlarged By I.S., 1626. Gravura em metal aquarelada s/ papel com polpa de trapo, 39,3 X 51,3 cm.

A0000387 - Guiana Fiue Amazonum Regio, 1633. Gravura em metal aquarelada s/ papel, 37,5 X $49 \mathrm{~cm}$.

A0000388 - A New and Accurat Map of the World, 1656 - 1659.

Gravura em metal aquarelada s/ papel com polpa de trapo, 39 X $51,9 \mathrm{~cm}$.

A0000390 - Sterre Kaert Of Hemels Pleyn, Waer Door Men Kawetehoelaet Dathetis Over de Gehele Aertkloot, Op Alle Meridiane en Polus Hoogte, en, Opwat Lengte en Brete de Voorsz Sterre Staen, Bezuyde en Benoorde de Liniae Aequinoctiael, s.d. Gravura em metal aquarelada s/ papel, 47,7 X 58,3 cm.

A0000391 - Corso del Fiume del Amazoni, Descritto Dal P. Cosmografo Coronelli, e Dedicato all'Illustrissimo Signore Alessandro de Verazzano Nobile Fiorentino, 1691. Gravura em metal s/ papel com polpa de trapo, 28 X 45,8 cm.

A0000392 - LAmerique Meridionale et Septentrionale, s.d. Gravura em metal aquarelada s/ papel com polpa de madeira, 46,3 X 59,6 cm.

A0000393 - The Great River Marañon or of the Amazons - Geographically Describ'd By Samuel Fritz Mifsioner on the Said River, s.d. Gravura em metal s/ papel com polpa de trapo, 15,7 X 39,7 cm.

A0000399 - Amérique Méridionale, s.d. Gravura em metal aquarelada s/ papel com polpa de madeira, 31,2 X 43,2 cm.

A0000400 - Carte du Bresil Prem. Partie Depuis la Riviere Des Amazones Jusqu'à la Baie de Tous Les Saints Pour Fervir à l'Histoire des Etablisfemens Europeens., 1772. Gravura em metal aquarelada s/ papel, 23,2 X $32 \mathrm{~cm}$.

A0000404 - Praefectura de Ciriii, vel Seregippe del Rey cum Itapuáma, 1665. Gravura em metal aquarelada s/ papel com polpa de trapo, 41,5 X 53,5 cm.

A0000453 - Brazil - John Tallis Et Company London \& New York (duas cópias em xerox colorido - em 19/12/2005 não havia o original), s.d. Impressão gráfica colorida s/ papel, 36,9 X 25,5 cm. 
A0000454 - [Latitudes com Zonas do Globo e Mapa Mundi] (fig. 13), s.d. Gravura em metal aquarelada s/ papel com polpa de trapo, 14,2 X 10,1 cm.

A0000456 - Carte Generale - Allgemeine Welt = Charten (fig. 7), s.d. Gravura em metal aquarelada s/ papel com polpa de trapo, 14,5 X 10,4 cm.

A0000457_A - Praefecturae de Paraiba, et Rio Grande, 1665. Gravura em metal aquarelada s/ papel com polpa de trapo, 42,2 X 54,1 cm.

A0000457_B - Praefecturae de Paraiba, et Rio Grande, 1665. Gravura em metal aquarelada s/ papel com polpa de trapo, 42,1 X 53,6 cm.

A0000459 - America Meridionalis, s.d. Gravura em metal aquarelada s/ papel com polpa de madeira.

A0000460 - Pascaert van Brasil - Littora Brasilliae, 1680. Gravura em metal aquarelada s/ papel com polpa de madeira.

A0000461 - Praefecturae Paranambucae pars Meridionalis, 1665. Gravura em metal aquarelada s/ papel com polpa de trapo, 42 X 44,2 cm.

A0000479 - Americae pars Meridionalis, s.d. Gravura em metal aquarelada s/ papel, 46,2 X 54,6 cm.

A0000481 - Le Bresil, Dont la Coste est Possedée par les Portugais et Divisée en Quatorze Capitanieres, 1656. Gravura em metal aquarelada s/ papel com polpa de trapo, 39,2 X 54,1 cm.

A0000482 - Pianta di S. Vincenzo, 1698. Gravura em metal aquarelada s/ papel, 37,8 X 50,7 cm.

A0000483 - Brasil Nuova Tavola, 1561. Gravura em metal aquarelada s/ papel com polpa de trapo, 18 X 25,5 cm.

A0000538 - Brasil, 1550. Gravura em metal aquarelada s/ papel com polpa de trapo, 27,2 X 37,3 cm.

A0000540 - Amerique Meridionale, 1670. Gravura em metal aquarelada s/ papel com polpa de madeira.

A0000543 - Map Shewing the Position of the Morro Tabac Cold Mine, Belonging to the Braganza Gold Mining Co., Limited, Relatively to the Mines of the S. John Del Rey, Don Pedro, N. Del Rey, Rossa Grande, Taquaril and Other Gold Mining Companies in the Province (...), 1868. Impressão gráfica p\&tb s/ papel, 23 X 19,9 cm.

A0000544_A - Brasilia Generis Nobilitate Armorum et Litterarum Scientia Prestant.mo Heroi Christoph Ab Artischav Arciszewski, 1673. Gravura em metal aquarelada s/ papel, 38,5 X 49,7 cm. 
A0000544_B - Brasilia, s.d. Gravura em metal aquarelada s/ papel com polpa de madeira.

A0000545 - Paskaert Van Brasilia van Pernambuco Tot C. de S. Antonio, s.d. Gravura em metal aquarelada s/ papel com polpa de trapo, 43 X 53,5 cm.

A0000546 - Recens Elaborata Mappa Geographica Regni Brasiliae In America Meridionali, 1740. Gravura em metal aquarelada s/ papel com polpa de trapo, 49,4 X 55,9 cm.

A0000547 - Amérique Méridionale par J. B. Poirson, s.d. Gravura em metal aquarelada s/ papel com polpa de trapo, 33 X 23,7 cm.

A0000551 - PasKaart van Brasil van Rio de los Amazones, tot Rio de la Plata, s.d. Gravura em metal aquarelada s/ papel com polpa de madeira.

A0000555_A - Kaart van de Aller-Heiligen Baay Waar aan de Hoofstad legt van Brazil, 1767. Gravura em metal aquarelada s/ papel com polpa de trapo, 34,3 X 40,5 cm.

A0000555_B - Kaart van de Aller-Heiligen Baay waar aan de Hoofstad legt van Brazil, s.d. Gravura em metal aquarelada s/ papel, 34,1 X 39,9 cm.

A0000558 - Brasilia Generis Nobilitate Armorum et Litterarum Scientia Prestant Mo Heroi Christoph: AB Artischav Arciszewski, s.d. Gravura em metal aquarelada s/ papel com polpa de trapo, 38,2 X 49,4 cm.

A0000559 - Paraguay, Ó Prov. De Rio de La Plata cum regionibus adjacentibus tucuman et Sta. Cruz de la Sierra, 1640. Gravura em metal aquarelada s/ papel.

A0000560_A - Americae Sive Novi Orbis, Nova Descriptio, s.d. Gravura em metal s/ papel, 35,3 X 48,3 cm.

A0000560_B - Americae Sive Novi Orbis, Nova Descriptio, s.d. Gravura em metal aquarelada s/ papel com polpa de trapo, 36,8 X 50,1 cm.

A0000561 - Orbis Terrarum Tabula Recens Emendata, 1679. Gravura em metal aquarelada s/ papel com polpa de trapo, $31 \mathrm{X} \mathrm{47,5} \mathrm{cm}$.

A0000562 - Accuratissima Brasiliae Tabula, 1663. Gravura em metal aquarelada s/ papel, 37,9 X $49 \mathrm{~cm}$.

A0000566 - Nova Totius Terrarum Orbis Geographica Ac Hydrographica Tabula, 1631. Gravura em metal aquarelada s/ papel com polpa de madeira. 
A0000567 - Nova Totius Americae Descriptio, s.d. Gravura em metal aquarelada s/ papel, 44 X 55,4 cm.

A0000568 - Plata Americae Provincia, s.d. Gravura em metal s/ papel com polpa de trapo, 22,8 X $28,7 \mathrm{~cm}$.

A0000569 - Carte du Cours du Maragnon ou de la Grande Riviere des Amazones, 1774. Gravura em metal s/ papel, 17,3 X 37,2 cm.

A0000572 - Carta Geografica Del Bresil, s.d. Gravura em metal s/ papel com polpa de madeira.

A0000575 - S.Salvador, 1671. Gravura em metal s/ papel com polpa de trapo, 30,5 X 37,7 cm.

A0000632 - Provincia de Brasil cum Adiacentibus Provinciis, s.d. Gravura em metal aquarelada s/ papel, 27,9 X 35,9 cm.

A0000667 - Mariner's Compass, 1776. Gravura em metal s/ papel com polpa de trapo, 16 X 15,8 cm.

A0000757 - East Coast of South America - Brazil, Middle Provinces, s.d. Impressão gráfica colorida s/ papel com polpa de madeira.

A0000758 - Imperial Federation - Map of the World Showing the Extent of the British Empire, 1886. Gravura em metal aquarelada s/ papel.

A0000759 - A General Map of the World or Terraqueous Globe, s.d. Gravura em metal aquarelada s/ papel com polpa de madeira, 103,7 X 123,1 cm.

A0000760 - Mappe Monde Contenant des Parties Connues de Globe Terrestre Dressée, 1754. Gravura em metal aquarelada s/ papel com polpa de trapo, 119,3 X 146,4 cm.

A0000761 - L'Amerique Divisée En Tous Ses Pays et Etats Dressée Sur de Nouveaux Memoires et Sur les Dernieres Obvservations, 1754. Gravura em metal aquarelada s/ papel com polpa de trapo, 118,6 X 147,3 cm.

A0000762 - L'Ámerique Divisée Selon Letendue de Ses Principales Parties, 1717. Gravura em metal s/ papel com polpa de trapo, 108,5 X 157,3 cm.

A0000763 - L'Afriqué Divisée en Tous Ses Etats Dressé Sur de Nouveaux Memoires et Suivant les Dernieres Observations, 1754. Gravura em metal aquarelada s/ papel com polpa de trapo, 118,1 X 148,2 cm.

A0000764 - L'Europe Divisée en Tous Ses Etats Dressée Sur de Nouveaux Memoires et Suivant les Dernieres Observations, s.d. Gravura em metal aquarelada s/ papel com polpa de trapo, 118,5 X $146,4 \mathrm{~cm}$. 
A0000765 - L'Asie Divisée en Tous Ses Etats Dressée Sur de Nouveaux Memoires et Suivant les Dernieris Observations, s.d. Gravura em metal aquarelada s/ papel com polpa de trapo, 118,7 X 148,3 cm.

A0000766 - Nova et Exacta Delineatio Americae Partis Australis. Que est: Brasilia, Caribana, Gviana Regnum Nouum Castilla del Oro, Nicaragua, Insulae Antillas et Perv. Et Subtropico Capricorni, Chile, Rio Della Plata, Patagonu \&t Fretv Magellanicu, 1599. Gravura em metal s/ papel com polpa de madeira.

A0000768 - Brasilia, s.d. Gravura em metal s/ papel com polpa de madeira.

A0000769 - Peru, s.d. Bico de pena s/ pergaminho, 30,2 X 21,1 cm.

A0000770 - Novus Brasiliae Typus, 1640. Gravura em metal aquarelada s/ papel com polpa de madeira.

A0000771 - Zuyder deel van America, s.d. Gravura em metal aquarelada s/ papel com polpa de madeira.

A0000772 - A Chart of the Sea Coast of Brazil From Cape St. Augustine to the Straights of Magellan, \& in the South Sea From the Lattitud of Eight Degress to the Faid Straights, s.d. Gravura em metal aquarelada s/ papel, 43 X 52,1 cm.

A0000773 - Brazile/ A New Description by Robt. Morden, 1686. Gravura em metal s/ papel, 12,1 X 10,2 cm.

A0000774_A - America Meridionale, s.d. Gravura em metal s/ papel com polpa de trapo, 60,8 X 45,4 cm.

A0000774_B - America Meridionale, s.d. Gravura em metal s/ papel com polpa de trapo, 60,4 X 45,2 cm.

A0000775 - Brasiliaanze Scheepvaard Door Johan Lerius, 1556. Gravura em metal s/ papel com polpa de madeira.

A0000777 - P. Carders Zee en Land Reyse na Brasil Rio de La Plata en de Zuyd Zee, 1707. Gravura em metal s/ papel com polpa de madeira, 16,4 X 23,7 cm.

A0000779 - Plan de La Baye et de la Ville de Rio-Janeiro, s.d. Gravura em metal s/ papel com polpa de madeira.

A0000780_A - Pas-Kaart. Van de Zee-Kuften. Van, Brazilia Tufschen Rio Coroipo en Rio Ponica, s.d. Gravura em metal s/ papel com polpa de trapo, 50,7 X 57,7 cm.

A0000780_B - Pas-Kaart. Van de Zee-Kuften van Brazilia, Tufschen Rio Coroipo en Rio Ponica, s.d. Gravura em metal s/ papel com polpa de trapo, 50,9 X 57,6 cm. 
A0000797 - Pas-Kaart. Van de Zee-Kuften van Brazilia Tufschen Rio das Contas en Cabo S. Thome, 1683. Gravura em metal s/ papel com polpa de trapo, 52,8 X 58,1 cm.

A0000798 - Pas-Kaart, van de Zee-Kuften van, Brazilia, Tufschen, C. S. Thome en I S Catharina, s.d. Gravura em metal s/ papel com polpa de madeira, 50,6 X 58,2 cm.

A0000799 - Pas-Kaart/ Van de Zee-Kusten van, Brazilia, Tuschen I. S. Catharina, en C. S. Anthonio, s.d. Gravura em metal s/ papel com polpa de madeira.

A0000800_A - Pas-Kaart, Van de Zee-Kuften, van, Brazilia, Tufschen Bahia Baxa, en Punto de Lucena, s.d. Gravura em metal s/ papel com polpa de trapo, 51,2 X $58 \mathrm{~cm}$.

A0000800_B - Pas-Kaart, Van de Zee-Kuften, van, Brazilia, Tufschen Bahia Baxa en Punto de Lucena, 1709. Gravura em metal s/ papel com polpa de trapo, 50,9 X 57,3 cm.

A0000801 - Paas-Kaart/ Van de Zee-Kuften van Brazilia, Tuschen Cabo S. Agostino en Rio Coroipo, s.d. Gravura em metal s/ papel com polpa de madeira.

A0000802 - Pas-Kaart, Van de Zee-Kuften, van, Brazilia, Tufschen, Rio Ponica en Rio das Contas, s.d. Gravura em metal s/ papel com polpa de trapo, 50,5 X 57,5 cm.

A0000803 - Pas-Kaart, van de Zee - Kuften, van, Brazilia, Tufschen, Cabo Noord, en Cabo de Cuma, s.d. Gravura em metal s/ papel com polpa de madeira, $51 \mathrm{X} 58,4 \mathrm{~cm}$.

A0000804 - Pas-Kaart, Van de Zee-Kuften van Brazilia Tuschen, Cabo de Cuma, en Bahia Baxa, 1683. Gravura em metal s/ papel com polpa de trapo, 50,6 X 57,5 cm.

A0000805_A - Pas-Kaart, Van de Zee-Kuften, van, Brazilia, Tufschen, Punto de Lucena en Cabo S. Augustino, 1734. Gravura em metal s/ papel, 51,2 X 58,2 cm.

A0000805_B - Pas-Kaart, Van de Zee-Kuften, van, Brazilia Tufschen, Punto de Lucena en Cabo S. Augustino, 1734. Gravura em metal s/ papel, 51,2 X 58,2 cm.

A0000806 - Mavritiopolis, Reciffa, et Circumiacentia Castra, 1647. Gravura em metal s/ papel com polpa de trapo, 38,7 X 50,3 cm.

A0000807 - Insula Antonij Vaazij, s.d. Gravura em metal s/ papel, 39,2 X 51,3 cm.

A0000808 - Civitas Olinda, s.d. Gravura em metal s/ papel com polpa de trapo, 39,4 X 50,9 cm. 
A0000809 - Praefecturae Paranambucae Pars Meridionalis, s.d. Gravura em metal s/ papel com polpa de trapo, 41,7 X 44,9 cm.

A0000810 - Urbs S. Ludovici in Maragnon, s.d. Gravura em metal s/ papel com polpa de trapo, 39,5 X 51,9 cm.

A0000811 - Civitas Loandae S.Pauli, s.d. Gravura em metal s/ papel com polpa de trapo, 39 X $51,5 \mathrm{~cm}$.

A0000813 - Provincia del Ré, 1698. Gravura em metal s/ papel com polpa de trapo.

A0000814 - Provincia di Paraiba, 1698. Gravura em metal s/ papel com polpa de trapo, 36,8 X 50,4 cm.

A0000815 - Capitania de Parayba, 1635. Gravura em metal s/ papel, 40,9 X 54,2 cm.

A0000816 - Veroveringe van Rio Grande, s.d. Gravura em metal s/ papel com polpa de madeira.

A0000817_A - [Vista e Planta da Villa D’Olinda de Pernanbuco], 1653. Gravura em metal s/ papel com polpa de trapo, 27,5 X 35,6 cm.

A0000817_B - Villa D Olinda D Pernanbuco, 1653. Gravura em metal s/ papel com polpa de trapo, 27,7 X 36,2 cm.

A0000828 - Afbeeldinge vande Cabo St. Augustin Met Haer Forten, 1653. Gravura em metal s/ papel, 28,4 X $37,3 \mathrm{~cm}$.

A0000829 - Prospetto Della Citta Mavizea Capitale Della Provincia de Pernambuco, s.d. Gravura em metal s/ papel com polpa de trapo, 36,2 X $102 \mathrm{~cm}$.

A0000830 - Plan de Fernanbouc a la Coste de Bresil Echelle d'une Demie Lieue, 1764. Gravura em metal aquarelada s/ papel, 23 X $18,2 \mathrm{~cm}$.

A0000832 - Urbs Salvador, 1671. Gravura em metal s/ papel com polpa de madeira, 28,6 X 35,1 cm.

A0000833 - t'Neemen van de Suyker Prysen Inde Bay de Tode los Sañtos, 1653. Gravura em metal s/ papel com polpa de trapo, 28,1 X 37,2 cm.

A0000834 - Carte De la Baye de Tous les Saints, 1764. Gravura em metal aquarelada s/ papel, 21,2 X 17,2 cm.

A0000835 - Entrée de la Riviere de St. Francois à la Coste de Bresil, 1764. Gravura em metal aquarelada s/ papel com polpa de trapo, 21,7 X 16,5 cm. 
A0000836 - Suite du Bresil depuis la Baye de Tous les Saints jusqu'a St. Paul. Pour servir à l'Histoire Génle des Voyages. Tiré de l'Amérique de M. Danville, 1761. Gravura em metal aquarelada s/ papel com polpa de trapo, 23,9 X 16,7 cm.

A0000837_A - Paraquariae Provinciae Soc. Jesu Cum Adiacentib' Novissima Descriptio, 1732. Gravura em metal aquarelada s/ papel, $71,5 \times 54 \mathrm{~cm}$.

A0000839 - [Trecho de mapa do Oriente Médio], s.d. Bico de pena s/ pergaminho.

A0000840 - Portolan Chart of the Mediterranean and Northern Europe, 1603. Bico de pena s/ pergaminho.

A0000841 - Tabula Nova Totius Orbis, 1529. Gravura em metal aquarelada s/ papel com polpa de trapo, 30,3 X 45,5 cm.

A0000842 - Das Erst General/ Inhaltend die Beschreibung (Primeira descrição geral do círculo terrestre), 1550 c. Xilogravura s/ papel trapo.

A0000843 - DieErst General Tafel/ Die Beschreibung und Den Cirekel des Gantzen Erdtrichs und Murs Innhaltende, 1588. Gravura em metal s/ papel.

A0000845 - Universi Orbis Descriptio Ad Usum Navigantium, s.d. Gravura em metal aquarelada s/ papel com polpa de trapo.

A0000846 - Die Gantze Welt in Einem Kleberbat... (O mundo inteiro numa folha de trevo), 1581. Xilogravura s/ papel trapo, 26,6 X 37,8 cm.

A0000848 - Hocqvod Continetomnia Scientia Habet Vocis, s.d. Gravura em metal s/ papel com polpa de madeira.

A0000849 - Americae Sive Novi Orbis, Nova Descriptio, s.d. Gravura em metal aquarelada s/ papel com polpa de madeira.

A0000852 - Description de las Yndias Occidentalis, s.d. Gravura em metal s/ papel.

A0000853 - La Descrittione di Tutto il Peru, s.d. Gravura em metal s/ papel.

A0000854 - Descrittione di Tvtto'l Mondo Terreno al Piv Moderno Stile del Nostro Tempo. - Universi Orbis Discriptio, s.d. Gravura em metal aquarelada s/ papel com polpa de trapo, 25 X 18,4 cm.

A0000855_A - America Sive Novus Orbis Respectv Evropaeorvm Inferior Globi Terrestris, 1596. Gravura em metal s/ papel, 32,5 X 39,3 cm. 
A0000855_B - America Sive Novus Orbis Respectv Evropaeorvm Inferior Globi Terrestris, 1596. Gravura em metal s/ papel com polpa de trapo, 33 X 39,8 cm.

A0000856 - Americae Pars Magis Cognita, 1592. Gravura em metal s/ papel com polpa de trapo, 46,4 X 44,2 cm.

A0000857 - XXXIIII. Descrittione dell'America, o dell'India Occidentale, s.d. Gravura em metal s/ papel, 13,4 X 17,1 cm.

A0000869 - Meridionalis Americae pars Quinque Regiones ab Hyspanis Dividitur, 1592 - 1610. Gravura em metal s/ papel com polpa de trapo.

A0000870 - Descriptio Americae, s.d. Gravura em metal s/ papel, 8,5 X $12,3 \mathrm{~cm}$.

A0000871 - Description de L'Amerique Avstrale, s.d. Gravura em metal s/ papel com polpa de trapo, 9,6 X 13,1 cm.

A0000872 - Carte de L'Amerique, s.d. Gravura em metal s/ papel com polpa de trapo, 38,4 X 49,5 cm.

A0000873 - Mappa Fluxus et Refluxus, 1660. Gravura em metal s/ papel.

A0000875 - Novillinia et Accuratillima Totius Americae Descriptio, s.d. Gravura em metal aquarelada s/ papel.

A0000876 - Novus Orbis Sive America Meridionalis et Septentrionalis, s.d. Gravura em metal aquarelada s/ papel com polpa de trapo, 46,8 X $58 \mathrm{~cm}$.

A0000877 - Recentissima Novi Orbis Sive Ameicae Septentrionalis et Meridionalis, s.d. Gravura em metal aquarelada s/ papel com polpa de trapo, 49,5 X 58,1 cm.

A0000878 - America Meridionale, s.d. Gravura em metal aquarelada s/ papel com polpa de trapo.

A0000879 - Mare del Sud Detto Altrimentti Mare Pacifico, s.d. Gravura em metal s/ papel com polpa de madeira, 45 X $60 \mathrm{~cm}$.

A0000880 - America Meridionalis, 1718. Gravura em metal aquarelada s/ papel com polpa de trapo, 31,7 X 41,6 cm.

A0000881 - Mappe Monde ou Carte Generale de la Terre, 1717. Gravura em metal aquarelada s/ papel, 22,7 X 33,8 cm.

A0000882 - Carte de La Terre Ferme, du Perou, du Bresil, et du Pays des Amazones, s.d. Gravura em metal aquarelada s/ papel com polpa de madeira, 39,9 X 52,3 cm. 
A0000890 - Mappe Monde qui Comprend les Nouvelles Decouvertes Faites Jusqu'a ce jour, 1767. Gravura em metal aquarelada s/ papel com polpa de trapo, 23 X 30,8 cm.

A0000891 - South America, 1749. Gravura em metal aquarelada s/ papel com polpa de trapo, 25,3 X 23,7 cm.

A0000893 - Tipus Orbis Terrarum, 1603. Gravura em metal s/ papel com polpa de madeira.

A0000894 - America Sive India Nova, 1595. Gravura em metal aquarelada s/ papel com polpa de trapo, 36,8 X 46,2 cm.

A0000895 - Al Sermo Ferdinando.II. Granduca di Toscana/ Suo Signore Don Roberto Dudleo Duca NorthUmbria XIII, s.d. Gravura em metal s/ papel com polpa de trapo.

A0000896 - Die Ebbe und Fluth Auff einer Flachen, s.d. Gravura em metal s/ papel.

A0000897 - Geographia Mosaica Generalis cum Novissima Orbister Raquei Facie et Commentariolis, s.d. Gravura em metal s/ papel.

A0000898 - Sitvs. Partivm Praecipvarvm Totivs Orbis Terrarvm, s.d. Gravura em metal s/ papel, 19,3 X 38,1 cm.

A0000899 - Mar di Aethiopia Vulgo Oceanus Aethiopicus, s.d. Gravura em metal aquarelada s/ papel com polpa de madeira.

A0000900 - Carte Tres Curieuse de La Merdu Sud, Continant des Remarques Nouvelles et Tres Uteles non Seulement Sur les Ports et Iles de Atte Mer [Mesma imagem do mapa A0001078]., 1720. Gravura em metal aquarelada s/ papel com polpa de trapo, 81 X 140,7 cm.

A0000901 - Mappe-Monde = Geo-Hydrographique ou Description Generale du Globe Terrestre et Aquatique en Deux-PlansHemispheres, ou Sont Exactement Remarques en General Toutes Les Parties de la Terre et de l'Eau, Suivant les Relations les Plus Nouvelles, s.d. Gravura em metal aquarelada s/ papel com polpa de trapo.

A0000903 - Planiglobium Terrestre Minus in Hanc Formam Reductam à Lohanne Bapt. Homanno Geogr. Excudente Christop Weigelio Noriber, s.d. Gravura em metal aquarelada s/ papel, 27,7 X 35,5 cm.

A0000904 - Novus Planiglobii Terrestris Per Utrumque Polum Conspectus, s.d. Gravura em metal aquarelada s/ papel com polpa de madeira. 
A0000905 - Planisphere Terrestre, Suivant les Nouvelles

Observations des Astronomes, 1715. Gravura em metal s/ papel com polpa de trapo.

A0000906 - A New Map of the World From the Latest Observations, s.d. Gravura em metal aquarelada s/ papel, 41,8 X 52,5 cm.

A0000907 - Globe de Mella/ Globe de Posidonius/ Globe de Ptolomee, s.d. Gravura em metal aquarelada s/ papel, 16,2 X $12,2 \mathrm{~cm}$.

A0000908 - Maris Pacifici, (Quod Vulgo Mar del Zur) Cum Regionibus Circumiacentibus, Insulisque in Eodem Passim Sparsis, Novissima Descriptio., s.d. Gravura em metal aquarelada s/ papel.

A0000909 - Le Nouveau Monde Descouvert et Illustre de Nostre Temps, 1581. Gravura em metal s/ papel com polpa de trapo.

A0000911 - Secunda Etas Mundi (Segunda Idade do Mundo), 1493. Xilogravura s/ papel trapo, 31 X 43,9 cm.

A0000912 - Sem titulo [Tabula terrae nouae], s.d. Gravura em metal s/ papel com polpa de trapo, 28,8 X 41,8 cm.

A0000913 - [Trecho recortado com mapa de Portugal], s.d. Bico de pena s/ pergaminho.

A0000915 - [Trecho Ásia - Europa - África], s.d. Bico de pena s/ pergaminho.

A0000922_A - Carte de la Terre Ferme du Perou, du Bresil et du Pays des Amazones, 1765. Gravura em metal aquarelada s/ papel com polpa de madeira.

A0000922_B - Tabula Geographica Peruae, Brasiliae \&t Amazonum Regionis, s.d. Gravura em metal aquarelada s/ papel, 49,2 X 57,7 cm.

A0000985 - Le Bresil, Suivant les Nouvelles Observations de Mess [1.s] de l'Academie Royale des Sciences, etc. Augmentées de Nouveau a Leide, chez Pierre Vander AA. - Avec Privilege, s.d. Gravura em metal aquarelada s/ papel com polpa de trapo, 26,2 X $38,3 \mathrm{~cm}$.

A0001064_A - Carte de la Partie Méridionale du Bresil Avec les Possesssions Espagnoles Voisines qui en Sont a l'ouest - par Mr. Bonne, Ingénieur-hydrographe de la Marine. ( $\left.n^{\circ} 34\right)$ - (mapa semelhante ao número A0001064_B), 1780. Gravura em metal aquarelada s/ papel, 22 X 32,2 cm. 
A0001064_B - Carte de la Partie Méridionale du Bresil Avec Les Possesssions Espagnoles Voisines Qui en Sont a l'Ouest - par Mr. Bonne, Ingénieur-hydrographe de la Marine. (n $\left.{ }^{\circ} 4\right)$ - (mapa semelhante ao número A0001064_A), 1780. Gravura em metal aquarelada s/ papel com polpa de trapo, 22 X 32,1 cm.

A0001070 - Carte de la Partie Meridionale de L'Amerique Meridionale, s.d. Gravura em metal aquarelada s/ papel com polpa de trapo, 48,1 X 45,9 cm.

A0001078 - A General Map of the World, 1794. Gravura em metal aquarelada s/ papel, 103 X $124 \mathrm{~cm}$.

A0001079 - Mappe-Monde Dressée Suivant les Nouvelles Relations et Assujettie Aux Observations Astronomiques, s.d. Gravura em metal aquarelada s/ papel com polpa de madeira.

A0001084 - Erdkarte in Mercators Projection. Zugleich als Karte v. Australien und Polynesien., s.d. Gravura em metal aquarelada s/ papel com polpa de madeira, 18 X $23 \mathrm{~cm}$.

A0001086 - Der Gantze Welt Krets in Seinen Zwey Grossen Begriffen als 1. Dem Neveren und 2. Dem Asteren - War Innen der Erste Meridian Nach Frantzofifcher artgezogen, s.d. Gravura em metal aquarelada s/ papel, 14,7 X $13 \mathrm{~cm}$.

A0001093 - Mappe Monde ou Carte Générale de L'Univers D’Après une projection nouvelle d'une sphére ovale, pour mieux faire connaitre les distances entre L'Europe et L'Amérique, Avec Les tours du Monde du Cap: Cook, et Toutes les Decouvertes Nouvelles, s.d. Gravura em metal aquarelada s/ papel com polpa de trapo, 48,5 X 93,5 cm.

A0001095 - South America with its Several divisions accordin to the Possesions of the European Powers, s.d. Gravura em metal aquarelada s/ papel com polpa de madeira, 44 X 53,2 cm.

A0001096 - Carthe du Premier Penode du Monde Depuis Adam Iusqu'Amoise oul 'on Voit la Chrondogie la Genealogie des Premiers Patnarches Avec Desremarques pour Conduire al'Intelligence de $l$ 'Histoire Sacrée, s.d. Gravura em metal aquarelada s/ papel com polpa de madeira, 37,2 X 47,6 cm.

A0001098 - L'Amerique Divisée en Fes Principaux Etats, s.d. Gravura em metal aquarelada s/ papel.

A0001099 - Map of Part of the Provinces of Rio de Janeiro and the Minas Geraes With the Authors Route, s.d. Gravura em metal aquarelada s/ papel, 36,7 X 47,9 cm.

A0001100 - Brazil and Paraguay, s.d. Gravura em metal aquarelada s/ papel com polpa de madeira. 
A0001101 - A Map of Brazil Now Called New Portugal, 1814. Gravura em metal aquarelada s/ papel, 44,4 X 35,7 cm.

A0001104_A - Portugallia et Algarbia Regna, s.d. Gravura em metal aquarelada s/ papel.

A0001104_B - Portugalliae et Algarbiae Regna, s.d. Gravura em metal aquarelada s/ papel com polpa de trapo, 49,5 X $58 \mathrm{~cm}$.

A0001105 - Brésil et Pays des Amazones, Avec le Gouvernement de Buenos-Ayres. 2me. Feuille. Par M. Bonne, Ingénr. Hydrographe de la Marine, s.d. Gravura em metal s/ papel com polpa de trapo, 24,4 X 34,5 cm.

A0001106 - Plan de L'Isle et du Port de Ste. Catherine, Située en la Côte du Bresil et dans les Possessions Portugaises: Avec l'Indication des Principaux Forts, Retranchemens et Batteries qui la Défendoient, à l'Arrivée de l'Escadre Espagnole qui s'em Empara le[...], 1777. Gravura em metal aquarelada s/ papel, 26,6 X 46,2 cm.

A0001107 - Carte du Brésil, Dressée Pouo l'Intelligence de l'Histoire Générale des Voyages de Labarpe, 1821. Gravura em metal aquarelada s/ papel com polpa de trapo, 55,3 X 41,1 cm.

A0001109_A - Empire du Brésil, Divisé en 20 Provinces - Atlas Sphéroïdal \&t Universel de Geographie, 1860. Gravura em metal aquarelada s/ papel com polpa de madeira, 47,5 X $34 \mathrm{~cm}$.

A0001109_B - Empire du Brésil, Divisé en 20 Provinces - Atlas Sphéroïdal \&t Universel de Geographie, 1860. Gravura em metal aquarelada s/ papel com polpa de madeira, 47,3 X 34,1 cm.

A0001110 - Süd-Amerika, in 6 Blättern, s.d. Gravura em metal aquarelada s/ papel com polpa de madeira, 34,3 X 42,1 cm.

A0001111 - Chemin de Fer São Paulo - Rio Grande \&t Port de São Francisco - Brésil, 1905. Impressão gráfica colorida s/ papel com polpa de madeira, 21,7 X 29,8 cm.

A0001112_A - Carte du Brésil, 1838. Gravura em metal aquarelada s/ papel, 56 X 39,8 cm.

A0001112_B - Carte du Brésil, 1829. Gravura em metal aquarelada s/ papel, 55 X 39,7 cm.

A0001115 - Brasilien Guyana - Paraguay u. Montevideo, s.d. Gravura em metal aquarelada s/ papel, 14,1 X 8,7 cm.

A0001118 - L'Amérique Meridionale, s.d. Gravura em metal aquarelada s/ papel.

A0001124 - The Great and Small Bay of le Grande. Part of Brazile At c., 1750. Gravura em metal aquarelada s/ papel com polpa de trapo, 16,5 X 20,8 cm. 
A0001125 - Ville de Saint Salvador Capitale du Bresil Echelle de Trois Cent Toises - Baye de Touts les Saints, 1771. Gravura em metal aquarelada s/ papel com polpa de trapo, 16,4 X 31,9 cm.

A0001127Carte des Isles du Salut Autrefois les Isles au Diable, 1764. Gravura em metal aquarelada s/ papel, 22,4 X 17,6 cm.

A0001128 - Empire du Brésil, 1848. Gravura em metal colorida com caneta porosa s/ papel com polpa de, 31,2 X 23,1 cm.

A0001129 - Brésil et Pays des Amazones - 1re. Feuille - par M.

Bonne, Ingénieur-hydrographe de la Marine., s.d. Gravura em metal aquarelada s/ papel com polpa de trapo, 23,5 X 37,3 cm.

A0001130_A - Carte de la Partie Septentrionale du Bresil - par Mr. Bonne, Ingénieur-hydrographe de la Marine. ( $n^{\circ}$ 35) - (mapa semelhante ao número A0001130_B e C), 1788. Gravura em metal aquarelada s/ papel com polpa de trapo, 21,2 X 31,7 cm.

A0001130_B - Carte de la Partie Septentrionale du Bresil - par Mr. Bonne, Ingénieur-hydrographe de la Marine. ( $\left.n^{\circ} 35\right)$ - (mapa semelhante ao número A0001130_A e C), 1788. Gravura em metal aquarelada s/ papel com polpa de trapo, 22 X 32,2 cm.

A0001130_C - Carte de la Partie Septentrionale du Bresil - par Mr. Bonne, Ingénieur-hydrographe de la Marine. (n 35) - (mapa semelhante ao número A0001130_A e B), 1788. Gravura em metal s/ papel com polpa de trapo, 21,5X $31,5 \mathrm{~cm}$.

A0001131_A - Suite du Bresil pour Fervir à l Historie Générale des Voyages, s.d. Gravura em metal aquarelada s/ papel com polpa de trapo, 23,9 X $17 \mathrm{~cm}$.

A0001131_B - Suite du Bresil pour Fervir à l Historie Générale des Voyages, s.d. Gravura em metal aquarelada s/ papel com polpa de trapo, 23,5 X 17,1 cm.

A0001131_C - [Deuses, Mapa das Américas, Magellanus e Franciscus Pifardus], 1623. Gravura em metal s/ papel com polpa de trapo, 28,7 X 19,1 cm.

A0001132 - Süd-America. Nach den Neuesten u. besten/ Materialien Bearbeitet u. Gezeichnet von F. Handtke. Druck u. C. Flemming - GLOGAU, 1851. Gravura em metal aquarelada s/ papel com polpa de madeira, 36,6 X 27,5 cm.

A0001133 - Brazil, Bolivia, Peru, \&t Ecuador., s.d. Gravura em metal aquarelada s/ papel com polpa de madeira, 46,4 X 33,8 cm.

A0001135 - South America (Eastern Sheet), 1858. Impressão gráfica colorida s/ papel com polpa de madeira, 32,2 X 27,1 cm. 
A0001137 - Brasilien - Geographie, s.d. Gravura em metal aquarelada s/ papel com polpa de madeira, 32 X 44,4 cm.

A0001139 - Impero Brasiliano Dalle Più Recenti Mappe e Dall'Atl. Per l'Amer. di J. A. BUCHON per l'Atlante St. Geog. Polit. Letterario di A LE SAGE., 1830. Impressão gráfica colorida s/ papel com polpa de trapo, 33,4 X 47,4 cm.

A0001140_A - Brazil and Guayana, s.d. Impressão gráfica colorida s/ papel com polpa de madeira, 42 X $34,5 \mathrm{~cm}$.

A0001140_B - Colton's Brazil and Guayana, s.d. Impressão gráfica colorida s/ papel com polpa de madeira, 42 X 34,5 cm.

A0001140_C - Colton's Brazil and Guayana, s.d. Impressão gráfica colorida s/ papel, $41,5 \times 34,5 \mathrm{~cm}$.

A0001141 - Brazil and Guiana, s.d. Impressão gráfica colorida s/ papel com polpa de madeira, 66,5 X 49,5 cm.

A0001146 - Der Atlantische Ocean nadj Martin Behaim, s.d. Impressão gráfica p\&tb s/ papel com polpa de madeira, $6,8 \times 13,5 \mathrm{~cm}$.

A0001152 - Hémisphère Occidental, s.d. Gravura em metal aquarelada s/ papel com polpa de trapo.

A0001153 - A Chart of the Coast of Brazil and Guiana, in America: With Part of the Caribbe Islands, s.d. Gravura em metal aquarelada s/ papel com polpa de madeira.

A0001158 - Caerte van de Zeylage van Lacob le Maire Over de Zuydzee, Vertonende de Eylanden Ende Landen Aldaer by Hem Ghesien Ende Aenghedaen [...], s.d. Gravura em metal s/ papel com polpa de trapo, 22 X 52,1 cm.

A0001159 - Carte du Gouvernement de L'Amerique, C. XVII. Gravura em metal aquarelada s/ papel com polpa de madeira.

A0001160 - Södra - America, s.d. Gravura em metal aquarelada s/ papel com polpa de madeira, 20,8 X 22,8 cm.

A0001161 - Friburgum, s.d. Gravura em metal s/ papel, 38,9 X 49,9 cm.

A0001163 - A General and Particular Description of America., s.d. Impressão gráfica colorida s/ papel, $17,1 \mathrm{X} 18,6 \mathrm{~cm}$.

A0001164 - A Map of the New Continent According to Its Greatest Diametrical Lenght From the River la Plata to Beyond the Lake of the Afsiniboils, 1758. Gravura em metal aquarelada s/ papel com polpa de trapo, 21,5 X 17,4 cm. 
A0001165 - America Verfertiget von Foh. George Schreibern in Leipzig, s.d. Gravura em metal aquarelada s/ papel com polpa de trapo, 17 X 23,3 cm.

A0001167 - De L'Amerique en Général, s.d. Gravura em metal aquarelada s/ papel com polpa de trapo.

A0001168 - Plan de L'Histoire Universelle oùl'on Voit les Quatre Monarchies du Monde, et Tous les Anciens Etats Aussi Bien que Ceux qui Subsiste Aujourdhuy, 1744. Gravura em metal aquarelada s/ papel com polpa de madeira.

A0001169 - Ancien Continent - Das Alte Vefteland (fig. 80), s.d. Gravura em metal aquarelada s/ papel com polpa de trapo, 14,5 X 9,7 cm.

A0001170 - Erdkarte in Mercator's Projection. Zur Uebersicht der Christlichen Staaten und Ihrer Colonien. Gez. v. Hermann Berghaus., s.d. Gravura em metal aquarelada s/ papel, 33,2 X $37,8 \mathrm{~cm}$.

A0001171 - Geography, 1678. Gravura em metal s/ papel com polpa de trapo, 38,4 X $24 \mathrm{~cm}$.

A0001172 - Universi Terrarum Orbis Scriptorum Calamo Delineati Tomus Secundus - Orbis Veterls Descriptio, seu Ptolemaei Typvs, s.d. Impressão gráfica p\&tb s/ papel, 13,5 X 17,7 cm.

A0001173 - Mapa-Mundi en Dos Hemisferios, 1855. Gravura em metal aquarelada s/ papel com polpa de trapo, 18,2 X 28,7 cm.

A0001174 - Carte Réduite des Terres et des Mers du Globe Terrestre par M. Bonne, ingénieur-hydrographe de la Marine, 1782. Gravura em metal aquarelada s/ papel com polpa de trapo, 22,6 X 33,3 cm.

A0001180 - Amerique Meridionale Divisée en Ses Principales Parties ou Sont Distingués les Uns des Autres Les Estats Suivant qu'ils Appartienent Presentement aux François, Castillans, Portugais, Hollandois \&t Tirrée de Toutes Les Relations, qui Ont Paru Jusques [...], 1709. Gravura em metal aquarelada s/ papel com polpa de trapo, 45,8 X 64,8 cm.

A0001181 - L'Amerique Meridionale Dressée Fur les Observations de M.rs. De l'Academie Royale de Sciences \& Quelques Autres, \& Sur les Memoires le Plus Recens par G. de l'Isle, 1733. Gravura em metal aquarelada s/ papel com polpa de madeira.

A0001182 - Amerique Meridionale, s.d. Gravura em metal aquarelada s/ papel com polpa de trapo. 
A0001185 - A General Chart - Exhibiting the Discoveries Made by Captn James Cook in This and His Two Preceeding Voyages With the Tracks of the Ships Under His Command, s.d. Gravura em metal s/ papel com polpa de trapo, 57 X $91 \mathrm{~cm}$.

A0001187 - Tabula Totius Orbis Terrarum Exhibens Declinationes Magneticas Prout Observatae Funt Anno 1744 una cum Ventis Generalibus, 1744. Gravura em metal s/ papel, 20,5 X 48,4 cm.

A0001188 - Lacs, Fleuves, Rivieres et Principales Montagnes de L'Amerique, 1787. Gravura em metal aquarelada s/ papel com polpa de trapo.

A0001189 - Carta particolare della Brasilia che Comineia con il =Capo St. Antonio et Finisce Con Il Porto Del Spirito Sancto, s.d. Gravura em metal s/ papel com polpa de madeira, 48,4 X 75,3 cm.

A0001190 - Carta Particolare Della Brasilia Settentrionale, s.d. Gravura em metal s/ papel com polpa de madeira.

A0001191 - A New Chart of the Coast of Brazil - From the Banks of St. Roque, to the Island of St. Sebastian; With the Islands and Soundings in the Offing. From the Portuguese and Dutch Draughts and the Journals of the British Navigators, s.d. Gravura em metal s/ papel com polpa de trapo, 87,3 X $57 \mathrm{~cm}$.

A0001193 - Paralleles de Latitude, 1683. Gravura em metal aquarelada s/ papel com polpa de trapo, 15,1 X 10,4 cm.

A0001194 - South America. Gravura em metal aquarelada s/ papel com polpa de trapo, 18 X $23 \mathrm{~cm}$.

A0001195 - South America (Reduced From the Sheet Map), 1813. Gravura em metal aquarelada s/ papel com polpa de trapo, 28,3 X 22,2 cm.

A0001197 - South America, s.d. Gravura em metal aquarelada s/ papel com polpa de madeira, 27,4 X 32,3 cm.

A0001198 - A New Map of South America From the Best Authorities. By John Lodge., 1785. Gravura em metal aquarelada s/ papel, 33,1 X 36,3 cm.

A0001199 - South America, 1782. Gravura em metal aquarelada s/ papel com polpa de trapo, 36,3 X 35,9 cm.

A0001200 - South America, 1822. Gravura em metal aquarelada s/ papel com polpa de trapo, 43,3 X 54,1 cm.

A0001202 - South America From the Latest Discoveries/ Shewing the Spanish \& Portuguese Settlements - According to mr. D'Anville, 1775. Gravura em metal aquarelada s/ papel com polpa de trapo, 47,1 X 57,3 cm. 
A0001203 - Nouvelle Carte de Geographie de la Partie Meridionale de L'Amerique Suivant les Plus Nouvelles Observations Avec des Tables et des Remarques pour L'Intelligence de L'Histoire et de la Geographie, 1710. Gravura em metal aquarelada s/ papel com polpa de madeira.

A0001205 - Chart of North Atlantic Ocean - With Tracks of the Shipping to West Indies, North America \&t Cc., 1815. Gravura em metal aquarelada s/ papel com polpa de madeira.

A0001206 - Guiana Fiue Amazonum Regio, s.d. Gravura em metal s/ papel com polpa de madeira.

A0001209 - 't Suyder-Deel van America, 1679. Gravura em metal s/ papel.

A0001210 - Provincia de Brasil cum Adiacentibvs Provinciis, s.d. Gravura em metal s/ papel com polpa de trapo, 28,1 X 35,8 cm.

A0001226 - Carte D'Amerique Dresseé pour I'usage du Roy/ America Accurate in Imperia, Regna, Status \& Populos Divisa, Ad Usum Ludovic XV, Galliarum Regis, 1755. Gravura em metal aquarelada s/ papel com polpa de madeira, 49,5 X $60 \mathrm{~cm}$.

A0001432 - [Mapa Mundi], s.d. Impressão gráfica colorida s/ papel com polpa de trapo, 10,4 X 14,3 cm.

A0001433 - Climats Selon les Anciens - Die Himels Striche Nach der Alten Meinung (fig. 14), 1625. Gravura em metal aquarelada s/ papel com polpa de trapo, 14,2 X 10,2 cm.

A0001434_A - Ancien Continent - Avec Plusiers Isles, 1683. Gravura em metal s/ papel com polpa de trapo, 14,3 X 10,1 cm.

A0001434_B - Ancien Continent - Avec Plusiers Isles, 1683. Gravura em metal aquarelada s/ papel com polpa de trapo.

A0001435 - A Map of Terra Firma Peru, Amazoneland, Brasil \&t the North P. of La Plata, 1729. Gravura em metal aquarelada s/ papel com polpa de trapo, 20,5 X 27,5 cm.

A0001436 - Motus in Coelo Spirales, s.d. Gravura em metal aquarelada s/ papel com polpa de trapo.

A0001442 - Le Paraguayr Le Chili. La Terre, et Les Isles magellanicques, 1656. Gravura em metal aquarelada s/ papel com polpa de trapo, 40,2 X $50 \mathrm{~cm}$.

A0001450 - Le Globe Terrestre Representé en Deux Planshemispheres, 1719. Gravura em metal aquarelada s/ papel com polpa de trapo, 16,3 X 21,9 cm.

A0001452 - L'Amerique Meridionale, s.d. Gravura em metal aquarelada s/ papel, 47,4 X 58,2 cm. 
A0001502 - Brasil, 1863. Gravura em metal aquarelada s/ papel com polpa de madeira, 35,8 X 39,5 cm.

A0001508 - Suite du Bresil Pour Fervir a l'Histoire Generale des Voyages, s.d. Gravura em metal s/ papel, 23,5 X 17,1 cm.

A0001510 - Map of South America Engraved to Illustrate Mitchell's Shool and Family Geography, 1853. Impressão gráfica colorida s/ papel com polpa de madeira, 26,8 X $20 \mathrm{~cm}$.

A0001514 - Mappa da Provincia de San Pedro Reduzido Segundo uma Carta Manuscripta Levantada Debaxo da Direcçao. do Illmo. e Exmo. Snr. Visconde de S.Leopoldo., s.d. Gravura em metal s/ papel com polpa de trapo, 54,3 X 67,9 cm.

A0001516 - Primeiro Mappa da Costa do Brazil - Organizado por João Ruysch Segundo as Notas Fornecidas por Americo Vespucio e Publicado na Edicção da Geographia de Ptolomeu no Ano de 1508 em Roma, s.d. Impressão gráfica p\&tb s/ papel com polpa de madeira.

A0001534 - Sem título [Bacia Hidrográfica dos Rios Paraná, Uruguai e Iguaçú], s.d. Caneta e lápis de cor s/ papel com polpa de madeira.

A0001575 - A General Map of South America From the Best Surveys, 1796. Gravura em metal aquarelada s/ papel com polpa de madeira, 36 X 44,4 cm.

A0001590 - Folha de São Paulo - Tendências Debates - Ibirapuera [texto de Oscar Niemeyer], 2000. Impressão gráfica colorida s/ papel.

A0002138 - Troncos de Cien Leguas de Diferentes Paralelos, s.d. Gravura em metal aquarelada s/ papel, 41,5 X 53,1 cm.

A0002144 - Plan de la Ville de St. Salvador - Capitale du Bresil Scituée Dans la Baye de Tous les Saints par 12d 45' de Latitude Australe, 1714. Gravura em metal aquarelada s/ papel com polpa de trapo, 19,6 X 29,7 cm.

A0002145 - Carte Particuliere de L'Isle de Ste. Catherine Située à la Côte du Bresil par 27d. 30 de l'atitude Australe., s.d. Gravura em metal aquarelada s/ papel com polpa de trapo, 18,3 X 28,7 cm.

A0002146 - Pianta dell'isola, e della Rada di Fernando de Noronha, 1837. Gravura em metal aquarelada s/ papel com polpa de trapo, 30,1 X $27,1 \mathrm{~cm}$.

A0002150 - South America, 1820. Gravura em metal aquarelada s/ papel com polpa de madeira, 24,1 X 18,9 cm.

A0002200 - Nova Italiae Delineattio, 1680. Gravura em metal s/ papel com polpa de trapo, 38 X 49,7 cm. 
A0002318 - Planta dos Rios "Jary e Martins" Levantada na Exploração Organizada por: Sr. Cel. Manoel C. Ferra. Martins, Marcos de Carvalho, e Capm. Wenceslaó [da] Bohemia [ilegível] de 1895 a 1896, 1895. Tinta de caneta s/ tecido de cambraia com cola animal.

A0002367 - Païs qui sont aux Environs de la Riviere de la Plata et du Païs des Patagons, 1683. Gravura em metal aquarelada s/ papel com polpa de trapo, 15,5 X $10 \mathrm{~cm}$.

A0002368 - Amerique Meridionale, 1683. Gravura em metal s/ papel com polpa de trapo, 17,5 X $10 \mathrm{~cm}$.

A0002369 - Bresil - De L'Amerique - Figura CLIV, 1683. Gravura em metal aquarelada s/ papel com polpa de trapo, 16,5 X 10,5 cm.

A0002371 - Suite du Bresil Depuis la Baye de Tous les Saints jusqu'a St. Paul, 1764. Gravura em metal aquarelada s/ papel com polpa de trapo, 24,2 X 16,7 cm.

A0002372 - La Plata, s.d. Gravura em metal s/ papel, $10 \mathrm{X} 12,2 \mathrm{~cm}$.

A0002373 - Bresil, s.d. Gravura em metal s/ papel, 10 X 12,4 cm. A0002378 - Carte Generale de L'Empiré du Brésil, 1826. Gravura em metal aquarelada s/ papel, 35,3 X 30,7 cm.

A0002379 - Carte du Brésil, 1851. Gravura em metal aquarelada s/ papel, 55,7 X 40,1 cm.

A0002382 - Brasil, Waarvan de Kust Door de Portugeezen Bezeten, en in Veertien Hooftgebieden Verdeelt Word, 1705. Gravura em metal aquarelada s/ papel com polpa de trapo, 19,8 X $27 \mathrm{~cm}$.

A0002384 - America Meridionalis, s.d. Gravura em metal aquarelada s/ papel com polpa de trapo, 15 X 19,3 cm.

A0002385 - Descriptio Freti Magellanci - Fretum ma Gellanicum, s.d. Gravura em metal s/ papel, 9,4 X 12,5 cm.

A0002386 - Peru, s.d. Gravura em metal s/ papel, 8,8 X 12,2 cm.

A0002387 - Chilli et Patagonum Regio - Descriptio Regni Chili, s.d. Gravura em metal s/ papel com polpa de trapo, 9 X 13,5 cm.

A0002388 - Brasilia - Descriptio Brasilie, s.d. Gravura em metal s/ papel com polpa de trapo, 9,2 X 12,5 cm.

A0002412 - Map of the Valley of the Amazon to Accompany Lt. Herndons's Report Drawn by H.C. Elliott, 1854. Gravura em metal aquarelada s/ papel com polpa de madeira. 
A0002413_A - Map of Gibbon's Report. Map Drawn by Lieut. Lardner Gibbon U.S. Navy to Accompany His Report (mapa encadernado com A0002413_B), 1854. Gravura em metal s/ papel com polpa de madeira.

A0002413_B - Map of Gibbon's Report. Map of the ANDES. Drawn by Lieut. Lardner Gibbon U.S. Navy to Accompany His eport (mapa encadernado com A0002413_A), 1854. Gravura em metal s/ papel.

A0002414 - Mappa do Baixo Juruá por Aug. Hilliges, 1905. Impressão gráfica p\&tb s/ papel com polpa de madeira.

A0002433 - Nueva, y Correcta Carta del Mar Pacifico ó del Sur, 1748. Gravura em metal s/ papel com polpa de madeira.

A0002434 - Partie du Brésil - Amér. Mérid. - n 10, 1825. Gravura em metal aquarelada s/ papel com polpa de trapo, 46,6 X $57 \mathrm{~cm}$.

A0002435 - Partie de La Plata - Amér. Mér. - n 31, 1825. Gravura em metal aquarelada s/ papel com polpa de trapo, 48,2 X 52,3 cm.

A0002436 - Partie de La Plata - Amer. Mér. - no 26, 1825. Gravura em metal aquarelada s/ papel com polpa de trapo, 47,2 X 53,9 cm.

A0002437 - Partie du Brésil - Amér. Mér. - $n^{\circ}$ 32, 1825. Gravura em metal aquarelada s/ papel com polpa de trapo, 47 X 52,1 cm.

A0002438 - Partie du Brésil - Amér. Mér. - n 18 [28], 1825. Gravura em metal aquarelada s/ papel com polpa de trapo, 48 X 57,8 cm.

A0002439 - Partie du Brésil - Amér. Mér. - n²7, 1825. Gravura em metal aquarelada s/ papel, 47,3 X 53,6 cm.

A0002440 - Partie du Brésil - Amér. Mér. - n²4, 1825. Gravura em metal aquarelada s/ papel com polpa de trapo, 48 X 56,1 cm.

A0002441 - Partie du Brésil - Amér. Mér. - n²3, 1825. Gravura em metal aquarelada s/ papel com polpa de trapo, 47,4 X $56 \mathrm{~cm}$.

A0002442 - Partie du Brésil - Amér. Mér. - n²2, 1825. Gravura em metal aquarelada s/ papel com polpa de trapo, 48 X 55,8 cm.

A0002443 - Partie du Brésil - Amér. Mér. - n 19, 1825. Gravura em metal aquarelada s/ papel com polpa de trapo, 47,7 X 56,7 cm.

A0002444 - Partie du Brésil - Amer. Mer. - $n^{\circ}$ 18, 1825. Gravura em metal aquarelada s/ papel com polpa de trapo, 47,8 X $57 \mathrm{~cm}$.

A0002445 - Partie du Brésil - Amér. Mér. - $n^{\circ}$ 17, 1825. Gravura em metal aquarelada s/ papel, $47 \mathrm{X} 56,5 \mathrm{~cm}$.

A0002446 - Partie du Brésil - Amér. Mér. - n 16, 1825. Gravura em metal aquarelada s/ papel com polpa de trapo, 47,3 X 62,7 cm. 
A0002447 - Partie du Pérou et du Brésil - Amér. Mér. - $n^{\circ}$ 15, 1825. Gravura em metal aquarelada s/ papel com polpa de trapo, 46,4 X $55 \mathrm{~cm}$.

A0002448 - Partie du Brésil - Amér. Mér. - n 12, 1825. Gravura em metal aquarelada s/ papel com polpa de trapo, 48 X 56,8 cm.

A0002449 - Partie du Brésil - Amér. Mérid. - $n^{\circ}$ 11, 1825. Gravura em metal aquarelada s/ papel com polpa de trapo, 47 X 56,6 cm.

A0002483 - [America], s.d. Impressão gráfica colorida s/ papel.

A0002484 - [Mapa-Mundi - prancha $n^{\circ} 15$ do Atlas Universal], 2000. Impressão gráfica colorida s/ papel com polpa de madeira.

A0002485 - Meridies, s.d. Impressão gráfica colorida s/ papel.

A0002486 - Meridies, s.d. Impressão gráfica colorida s/ papel.

A0002773 - Map of the Rivers Huallaga, Ucayali \&t Amazon From the Observations of Lieut. Wn. L. Herndon U.S.N. Drawn by John Tyssowski Dr. Lith. By A. Hooen \&t Co. Baltimore, Md., s.d. Gravura em metal s/ papel.

A0002774 - Plan del Curso de los Rios Huallaga y Ucayali y de la Pampa Del Sacramento. Levantado por el P. Fr. Manuel Sobreviela, Guardian del Colegio de Ocopa en 1790, 1830. Gravura em metal s/ papel.

A0002868 - A Gruta de Lourdes [nota fiscal datada de 1891], s.d. Impressão gráfica p\&tb s/ papel com polpa de madeira.

A0002879 - Irmandade de Sta. Phigenia Deve a Manoel Tavares Coelho d'Azevedo/ Armador da Capella Imperial/ Sucessor de Joaquim Ferreira Lopes Sobrinho (...), 1879. Impressão gráfica p\&tb s/ papel.

I0000017 - Mappe Monde, 1778. Gravura em metal s/ papel.

I0000023 - Sem Título [Mapa Mundi], s.d. Gravura em metal aquarelada s/ papel.

I0000024 - Chart of the World, s.d. Gravura em metal s/ papel.

I0000063 - Carte de la Mer du Sud et des Costes D’Amerique et D’Asie, Situées Sur Cette Mer/ Carte de la Mer du Nord et des Costes D'Amerique, D'Europe et D'Afrique, Situées Sur Cette Mer., 1713. Gravura em metal aquarelada s/ papel, 101 X 191,5 cm.

I0001254 - Francisco Pisarro, 1671. Gravura em metal s/ papel com polpa de trapo.

I0001366 - Siara, 1645. Gravura em metal s/ papel com polpa de trapo.

I0001367 - Primu Praelium Navale Inter I. Tamaricam et Goianam XII Ianuar, s.d. Gravura em metal s/ papel com polpa de trapo. 
I0001368 - Parayba, s.d. Gravura em metal s/ papel com polpa de trapo.

I0001369 - Classis Quae in Patriam Comitem Revexit, s.d. Gravura em metal s/ papel com polpa de trapo.

I0001370 - Garazu, s.d. Gravura em metal s/ papel com polpa de trapo.

I0001371 - Classis Navium Qua Hinc Discessit Comes Mauritius Praefectus, 1645. Gravura em metal s/ papel com polpa de trapo.

I0001372 - Arx Nassovii, 1645. Gravura em metal s/ papel com polpa de trapo.

I0001373 - Olinda, 1645. Gravura em metal s/ papel com polpa de trapo.

I0001582 - Map of the World - Peters Projection, s.d. Impressão gráfica colorida s/ papel, 73,2 X 113,3 cm.

I0001795 - Tertium Praelium Ad Paribam XIII Ian, s.d. Gravura em metal s/ papel com polpa de trapo.

I0001796 - I.Tamaraca., s.d. Gravura em metal s/ papel com polpa de trapo.

I0001797 - Icon Ciuitatis Campensis, Cuius Situs, Isulam Fluuium, Eleganti VenusFate, Decorat, s.d. Gravura em metal s/ papel, 33,1 X $49 \mathrm{~cm}$.

I0001798 - Ostium Flumines Paraybae, s.d. Gravura em metal s/ papel.

I0001988 - Serinhaim, s.d. Gravura em metal s/ papel, 29,4 X 35,7 cm.

I0002215 - [Mapa da África, Europa, Ásia e Oceania - chinês], s.d. Bico de pena aquarelado s/ papel, 119 X 89,8 cm.

I0002216 - [Mapa da América - chinês], s.d. Bico de pena aquarelado s/ papel, 117,3 X 89,3 cm.

I0003774_A - Des Terres Australes - I. D’Horn, s.d. Gravura em metal aquarelada s/ papel com polpa de trapo, 17,3 X 10,6 cm.

I0003774_B - Des Terres Australes - Dd Magellan, s.d. Gravura em metal aquarelada s/ papel com polpa de trapo, 16,5 X 10,8 cm.

I0003775_A - De LAmerique - S. Salvador, s.d. Gravura em metal aquarelada s/ papel, 15,4X 9,5 cm.

I0003775_B - De L'Amerique - Bresiliens, s.d. Gravura em metal aquarelada s/ papel, 15,7 X 9,9 cm.

M0011 - Haemisphaerium Australe Steelatum Antiquum, s.d. Gravura em metal aquarelada s/ papel com polpa de trapo, 38,5 X $51,6 \mathrm{~cm}$. 
M0017_A - Stellas Omnes in Coelo - Dignoscere - I, 1725. Gravura em metal aquarelada s/ papel com polpa de trapo, 34,6 X 36,2 cm.

M0017_B - Distantiam stellarum - e. tabulis - Cognoscere - II, 1725. Gravura em metal aquarelada s/ papel com polpa de trapo, 35,3 X 36,5 cm.

M0017_C - Cometarum Locum - In Tabulis Invenire - III, 1725. Gravura em metal aquarelada s/ papel com polpa de trapo, 34,6 X $36 \mathrm{~cm}$.

M0017_D - Ascensionem Rectam et Declimationem Stellarum Ope Tabularum Invenire - IV, 1725. Gravura em metal aquarelada s/ papel com polpa de trapo, 34,5 X 35,9 cm.

M0017_E - Longitudinem et Latitudinem - Astrorum Invenire - V, 1725. Gravura em metal aquarelada s/ papel com polpa de trapo, $34,5 \times 35,7 \mathrm{~cm}$.

M0017_F - Stellas Perpetuae Apparitionis - In Tabulis Invenire - VI, 1725. Gravura em metal aquarelada s/ papel com polpa de trapo, 34,6 X 36,5 cm.

M0017_G - Numeris Stellarum - VII, 1725. Gravura em metal aquarelada s/ papel com polpa de trapo, 33,9 X 39,8 cm.

M0017_H - Index Constellationum - VIII, 1725. Gravura em metal aquarelada s/ papel com polpa de trapo, 33,4 X 39,5 cm.

M0022 - Carte du Brésil, Prem. Partie Depuis la Riviere des Amazones Jusquá la Baye de Tous le Saints, 1746. Gravura em metal aquarelada s/ papel, 24 X 32,4 cm.

M0023 - Carte de L’Amérique Méridionale, s.d. Gravura em metal s/ papel com polpa de trapo, 44,8 X 32,5 cm.

M0030 - Carte Qui Représent la Partie Méridionale du Brésil et du Peru, le Chili Septentrional et le Paraguay, s.d. Gravura em metal aquarelada s/ papel com polpa de trapo, 47,8 X 67,8 cm.

M0035 - Der Alte Welt Begriff Beftehende in 3 Haubt Theilen als Africa Europa Asia Warinnen der Erfte Meridian Nach Hollandifcher Art Gezogen, s.d. Gravura em metal aquarelada s/ papel.

M0049 - A Map of South America, s.d. Gravura em metal aquarelada s/ papel com polpa de trapo, 72 X 50,5 cm.

M0050 - Lower Peru, Brazil \& Paraguay, s.d. Gravura em metal aquarelada s/ papel com polpa de madeira, 41,1 X $51 \mathrm{~cm}$.

M0060 - Kaart van Het Onderkoning Schap van Peru, Zig Witstrekkende Over Chili, Paraguay en Anderespaansche Landen: Als Ook van Brazil en Verdere Bezziting en van Portugal in Zuid-Amerika, s.d. Gravura em metal aquarelada s/ papel com polpa de trapo, 35,8 X 39,8 cm. 
M0068 - (Ancienne Colombie)/ Nle Grenade, Vénézuéla, Equateur/ Guianes, s.d. Gravura em metal aquarelada s/ papel com polpa de trapo, 34,4 X $53 \mathrm{~cm}$.

M0079 - Tabula Americae Specialis Geographica Regni Peru, Brasiliae, Terrae Firmae \& Reg. Amazonum, s.d. Gravura em metal aquarelada s/ papel com polpa de trapo, 48,3 X 57,1 cm.

M0083 - L’Amerique, Meridionale et Septentrionale, 1717. Gravura em metal aquarelada s/ papel com polpa de trapo, 22,7 X 33,8 cm.

M0097 - Totius Americae Septentrionalis et Meridionalis, 1720. Gravura em metal aquarelada s/ papel, 49 X 57,6 cm.

M0121 - Mappa Mondo o Vero Carta Generale del Globo Terestre, 1671. Gravura em metal aquarelada s/ papel, 37,9 X $56 \mathrm{~cm}$.

M0144 - Cartes des Provinces Unies des Pays Bas Connues Foubs le Nom de Hollande et Pays Circonvoifins, 1673. Gravura em metal s/ papel com polpa de trapo, 39,4 X 50,8 cm.

M0159 - A New Map of the World Showing the Course of Sr. Francis Drake, William Shouten And Capt. William Dampiers Voyages, 1705. Gravura em metal s/ papel, 30,4 X 55,1 cm.

M0160 - A New Map of the World, 1705. Gravura em metal s/ papel, 57,9 X 93,6 cm.

M0180 - Carta Del Ponente, 1673. Aquarela s/ pergaminho colado em encadernação de cartão rígido.

M0238 - L'Amerique Meridionale ou la Partie Meridionale des Indes Occidentales, 1704. Gravura em metal aquarelada s/ papel com polpa de trapo, 44,7 X 58,9 cm.

M0239 - Brasilia, 1597. Gravura em metal s/ papel, 22,2 X 28,8 cm. M0240 - A Map Of South America Containing Tierra Firma, Guayana, New Granada, Amazonia, Brasil, Peru, Paraguay, Chaco, Tucuman, Chili And Patagonia, 1775. Gravura em metal aquarelada s/ papel com polpa de trapo, 99,9 X 117,7 cm.

M0241 - America Meridionale - Divisa Ne' Fuoi Principali Stati/ Venezia, 1795. Gravura em metal aquarelada s/ papel, 31,8 X 41,5 cm.

M0255 - Carte de L'Ocean Meridional, 1746. Gravura em metal s/ papel, 35 X 45,9 cm.

M0259 - Brasil, 1758. Gravura em metal s/ papel, 9,1 X 6,4 cm.

M0355 - Americae tam Septentrionalis quam Meridionalis in Mappa Geographica Delineatio, s.d. Gravura em metal aquarelada s/ papel com polpa de trapo, 49,9 X 58,4 cm. 
X-IEB-0001 - Sem título, s.d. Impressão gráfica colorida s/ papel.

X-IEB-0002 - A Map of South America Containing Tierra-Firma, Guayana, New Granada, Amazonia, Brasil, Peru, Paraguay, Chaco, Tucuman, Chili and Patagonia, 1787. Gravura em metal s/ papel, 100,2 X 118,3 cm.

X-IEB-0004 - Sem título, s.d. Não identificada, 73,2 X 113,3 cm.

2.3 Exposição: MAPAS EM MOVIMENTO a criação de mundos imaginários

A partir do acervo inventariado, o desdobramento foi a mostra Mapas em movimento: a criação de mundos imaginários, feita com a curadoria das Professoras Íris Kantor e Beatriz Piccolotto Siqueira Bueno e grande participação de toda a equipe técnica do IEB. Na exposição, apresenta-se o universo da produção, circulação e consumo da cartografia impressa entre os séculos XVI e XIX.

0 roteiro da exposição enfoca três aspectos dos mapas: Gabinete de impressão: saberes e técnicas; Mapas e impérios: de Instrumentos de conquista ao imaginário imperial; Da dádiva à mercadoria: Circulação e consumo. A partir deste roteiro e de recursos de animação digital, produziu-se o vídeo homônimo da exposição, que mostra o caminho dos mapas desde o levantamento de dados em campo, até a sua chegada ao IEB, passando pelo ambiente das casas editorias e pela sua presença nos Gabinetes de Curiosidades de antiquários, nos palácios da nobreza e nas residências da burguesia.

A exposição apresenta aproximadamente 70 dos mapas sob guarda provisória do IEB, juntamente com quase 15 Atlas pertencentes ao acervo permanente do Instituto, os quais foram escolhidos por serem exemplares completos e não apenas suas folhas soltas destacadas como é o caso dos mapas provenientes do Banco Santos.

A exposição permanecerá aberta ao público de 25 de setembro de 2006 a 29 de abril de 2007. Em janeiro, já atingia um público de aproximadamente 500 visitantes, parte dos quais inserida no âmbito do programa educativo criado pelo IEB especificamente para a exposição.

\section{Conclusão}

A execução deste trabalho foi profundamente enriquecedora, pois as decisões e os trabalhos foram realizados em equipe 
- numa equipe de formação sólida -, tendo cada um de seus membros respondido, nos momentos de emergência, de acordo com a situação, sem se perder em discussões infindáveis.

Em face dos problemas enfrentados, criaram-se métodos de gerenciamento das peças; trabalhou-se na estabilização do estado de conservação; desenvolveu-se a exposição; etc. Tudo foi registrado ao longo do processo, desde a primeira visita até a visitação da exposição montada e o acondicionamento das peças em reserva técnica. A documentação fotográfica de todo o processo encontra-se disponível para consulta.

Este breve texto não dá conta do vulto do trabalho, pois estas poucas linhas se limitaram a narrar os procedimentos adotados em face da enormidade dos problemas. Vale lembrar que concomitantemente ao trabalho, as responsabilidades e atividades de cada um dos envolvidos junto ao IEB e, no caso de estagiários, junto a seus cursos, continuaram as mesmas. Contudo, o envolvimento de todos foi tamanho que a equipe formada se revelou coesa em prol da vinda deste acervo para o IEB, sensibilizada pela presença de uma documentação tão grande e de tamanho valor cultural em um galpão pós-inundado.

Mesmo correndo o risco de cometer o grave erro de esquecer algum personagem importante, apresentamos a seguir uma lista dos envolvidos nesta enorme empreitada: Lúcia Elena Thomé (Chefe do Serviço de Conservação e Restauro do IEB, coordenadora da equipe); Bianca Maria Abbade Dettino (Chefe da Coleção de Artes Visuais do IEB, coordenadora da equipe); Fátima Faria Gomes (especialista em conservação e restauro da Coleção de Artes Visuais do IEB), Milton Ohata (supervisor da Difusão Cultural e doutor em história), Dorivaldo Santana, Lúcia Helena de Souza, Rubens Borges Pinto, Alexandre Macedo Ferreira, Leonildo Oliva de Araújo, Joana Pereira Lima, José Roberto Galhardo, todos parte do corpo funcional do IEB; e os queridos e indispensáveis estagiários: Cibele Monteiro da Silva, William Toledo de Lima, Vanessa Cristina Garcia de Oliveira, Monica Gama, Lívia Benedetti Santos, Thais da Cunha Gomes, Kátia Matos Soares, Viviane Monteiro Silva, Juliana Massoni, Alessandra Barbosa, Erica Regina Ferrari, Olívia Brenga, Flora Rebollo, Priscila Moreno, Aline Nogueira e aqueles que esquecemos de aqui elencar. Além disso, é preciso mencionar a atuação do Professor István Jancsó (diretor do IEB na ocasião); dos Professores Marta Rossetti e Telê Ancona Lopez, que participaram da visita técnica inicial; e das Professoras Íris Kantor e Beatriz Piccolotto Siqueira Bueno, que pesquisaram os mapas e foram curadoras da exposição. Por fim, mesmo que à distância, o maior responsável pelo trabalho foi quem assinou a corajosa decisão de destinar o acervo para a universidade: o Juiz Federal Fausto de Sanctis. 